\title{
SISTEM PENUNJANG KEPUTUSAN PENENTUAN JENIS TANAMAN HIAS DI TAMAN KOTA
}

\author{
Luki Hernando $^{1^{*}}$, Yopy Mardiansyah ${ }^{2}$ \\ ${ }^{1}$ Teknik Komputer, Institut Teknologi Batam \\ ${ }^{2}$ Teknik Industri, Intitut Teknologi Batam \\ email: *1uki@iteba.ac.id
}

\begin{abstract}
Currently in almost every city around the world that loves flowers, including ornamental plants,. All cities are aggressively arranging their landscaping to compensate for motorized vehicle pollution or the arrangement of city parks planted with decorative gardens with the aim of greening the city. Sometimes there are problems in making decisions to determine suitable and good ornamental plants for planting in the city, in a decision that takes a long time. Determination of the types of ornamental plants to be planted through several factors such as leaf shape, color, stems and branches, roots and soil. On these issues, the authors conducted research on the determination of ornamental plants for city parks in the form of a decision support system application using the Analytical Hoerarchy Process (AHP) method.
\end{abstract}

Keywords: analytical hoerarchy process (AHP); decision support system (SPK),

\begin{abstract}
Abstrak: Saat ini hampir di setiap kota di seluruh dunia yang menyukai bunga termasuk tanaman hias, Semua kota gencar menata pertamanannya untuk mengimbangi polusi kendaraan bermotor maupun untuk penataan taman kota yang ditanami tamanan hias bertujuan untuk menghijaukan kota. Terkadang terdapat masalah dalam pengambilan keputusan untuk menentukan tanaman hias yang cocok dan bagus umtuk ditanam pad ataman kota, dalam pengambilan keputusan yang dilakukan terkadang memakan waktu yang cukup lama . Penentuan jenis tanaman hias yang akan ditanam melalui beberapa faktor seperti bentuk daun, warna, batang dan cabang, akar dan Tanah. Atas permasalahan tersebut penulis melakukan penelitian tentang penentuan tanaman hias untuk taman kota yang berupa aplikasi sistem pendukug keputusan yang menggunakan metode Analytical Hoerarchy Process (AHP).
\end{abstract}

Kata kunci: proses analisis hirarkie (AHP); sistem pendukung keputusan (SPK) 
Available online at http://jurnal.stmikroyal.ac.id/index.php/jurteksi

\section{PENDAHULUAN}

Di zaman sekarang ini perkembangan teknologi sangatlah pesat, yang dapat membantu dan meringatkan pekerjaan kita sesuai dengan kebutuhan yang diinginkan oleh pemakai (user), baik dalam kebutuhan sehari-hari maupun dalam kebutuhan bisni dan usaha. Teknologi Informasi berperan sangat penting dalam kehidupan manusia baik didunia kerja maupun didunia pendidikan, yang sangat mempermudah dan membantu dalam menyelesaiakn pekerjaan dan mendapatkan infromasi yang bermanfaat. [1]

Teknologi informasi dan komunikasi merupakan salah satu konsep yang tidak bisa dipisahkan. Semua kegiatan yang berkaitan dengan manipulasi, proses, pemindahan informasi dari berbagai media dan pengolahan data disebut dengan TIK, setiap manusia tidak akan bisa menghindari dari perkembangan teknologi sekarang ini.[2]

Seiring dengan berkembangnya teknologi informasi membuat pola pikir, gaya hidup dan pola pandang sebagian masyarakat yang ada di Indonesia baik dalam menjalankan aktivitas maupun kegiatanya lainya. Teknologi informasi sangat berperan penting dalam kehidupan maupun pendidikan, akan tetapi perkembengan teknologi belum bisa diimbangi dengan sumber daya yang ada, hal ini disebabkan masih banyaknya sumber data yang belum bisa memanfaatkan teknologi informasi dalam kehidupan maupun pendidikan. [3]

Sistem Pendukung Keputusan (SPK) dibuat atau dirancang sebagus mungkin guna untuk membantu dalam pengemabilan keputusan yang melibatkan masalah - masalah rumit dan kompleks. SPK dirancang dalam pengambilan keputusan sekali saja yang jarang dibuat maupun keputusan yang jarang muncul.[4]

SPK merupakan suatu sistem yang dirancang dalam menyelesaikan berbagai masalah baik dalam organisasi maupun manajerial yang dirancang khusus untuk membantu manajer dalam pengambilan keputusan dan menyelesaikan permasalahan dalam perusahaan yang memanfaatkan perkembangan teknologi informasi, SPK hanya membantu sebagai bahan pertimbangan dalam pengambilan keputusan bagi para pimpinan untuk menentukan keputusan yang terbaik.[5]

S. Scott Morton memperkenalkan pertama kalinya SPK pada tahun 1970an, atau bisa disebut juga dengan Decision Support Systems, Kemudian SPK juga dikenal dengan istilah Management Decision Systems [6]. SPK merupakan pengambil keputusan menggunakan sebuah sistem yang bisa meringankan dalam membuat keputusan yang cepat dan akurat yang sifatnyat tidak terstruktur maupun terstruktur. Sistem ini tidak sepunuhnya untuk mengambil keputusan melainkan membantu mendukung dalam pengambilan suatu keputusan. Proses Pengambilan Keputusan dapat menggunakan beberapa model keputusan dan data yang akan menyelesaikan informasi yang dibutuhkan. [7]

SPK suatu sistem informasi yang dirancang berbasis komputer namun dapat memberikan solusi kepada orang yang mau mengambil keputusan dan pembuat keputusan. SPK dikembangkan dari Sistem Informasi Manajemen Terkomputerisasi, yang bertujuan memperumudah pemakainya. [8]

Decision Support System hanya mambantu dalam melakukan pengambilan keputusan bagi para pemangku kepentinngan atau perusahaan yang sangat tepat, akurat dan bijak guna menghasilkan nilai tambah bagi perus- 
Available online at http://jurnal.stmikroyal.ac.id/index.php/jurteksi

ahaan. [9]

Decision Support System adalah sistem yang dirancang untuk melakukan suatu proses evaluasi pengetahuan juga prefensi dalam melakukan pengambilan keputusan juga dengan dibantu oleh nilai sains. DSS tidak akan menggantikan peran pimpinan dalam pengambilan keputusan[10]. DSS ataupun SPK hanya membantu memecahkan masalah dan mengambil keputusan yang cukup rumit melainkan second opinion terhadap keputusan yang diambil. Decision Support System hanya sebuah perangkat lunak yang membantu dalam pengambilan keputusan dan membantu dalam memecahkan masalah.

SPK sangatlah penting bagi perusahaan maupun masyarakat biasa dalam mengambil keputusan yang cukup rumit, SPK sangat membantu dalam perkembangan perusahaan dikarenakan SPK dapat memberikan solusi yang akurat demi kemanjuan perusahaan dan dalam pengambilan keputusan tidak memerlukan waktu yang cukup lama.

Kebutuhan akan tanaman hias untuk taman kota sangatlah penting untuk penghijauan. Tanaman hias sangatlah dibutuhkan walaupun tujuan dari penanaman tanaman hias ini berbeda - beda. Dalam melakukan pemilihan tanaman hias ada beberapa kriteria berdasarkan penampilanya seperti bentuk daun yang cantik dan segar, warna tanaman yang dapat menyegarkan mata, berdasarkan batang dan cabang kuat atau tidaknya batang, berdasarkan kekuatan akar dan kelembaban tanah untuk tanaman hias.

Saat ini banyaknya peminat tanaman hias, baik kebutuhan sekunder maupun kebutuhan lainya. Seperti penanaman tanaman hias di Taman Kota yang dapat mempercantik taman dan membuat mata lebih terasa nyaman dan damai, membuat sebagian orang betah berada dilingkungan taman yang ditanami tanaman hias.

Penelitian yang dilakukan bertujuan untuk menentukan prioritas tanaman hias yang cocok ditanama pada taman kota, berdasarkan banyaknya peminat atau tingkat kesukaan masyarakat dengan tanaman hias dan kesesuaian selera orang dalam menentukan tanaman hias.

\section{METODE}

Analytical Hierarchy Process (AHP) merupakan suatu metode pendukung keputusan menyelesaikan masalah multi kriteria maupun multi factor yang komples yang dapat membentuk suatu hirarki, AHP dikembangkan oleh seorang ilmuan yang bernama Thomas L. Saaty mendefenisikan hierarki sebagai reprenstasi dari suatu permasalahan dari struktur multilevel yang pertama merupakan tujuan, level factor, level kriteria, level sub kriteria, dan level terakir dari alternative. [11]

Banyak orang yang menggunakan Analytical Hierarchy Process (AHP) karena dapat membantu dalam pemecahan masalah dibandingkan metode lainya, dengan pertimbangan sebagai berikut :

1. AHP mempunyai struktur yang berhierarki yang samapai pada sub kriteria yang paling terakhir.

2. Dapat melakukan perhitungan validasi sampai batas tolrenasi inkonsistensi yang berperan sebagai alternatif dan kriteria yang dilakukan atau dipilih oleh seorang pengambil keputusan

AHP (Analytical Hierarchy Process) adalah sebuah hierarki yang memiliki input ataupun masukuan yang palin utama dalam pandangan manusia. Prof. Thomas Lories Sati yang berasal dari Wharton Business School melakukan 
pengembangan dari metode AHP pada awal tahun 1970. AHP digunakan dalam menentukan urutan ranking dan AHP banyak digunakan dalam pengambilan keputusan yang efektif dan akurat. [12]

\section{HASIL DAN PEMBAHASAN}

Dalam penelitian ini terdapat beberapa sampel seperti Lima macam kriteria Untuk Tanaman hias yaitu Daun Tanaman Hias (K1), Warna tanaman (K2), Batang juga Cabang (K3), Akar dan (K4), Tanah (K5). Kemudian terdapat lima alternatif tanaman hias yaitu : Aglonema (B1), Monstera (Janda Bolong) (B2), Gelombang Cinta (B3), Kaktus dan (B4), Kaladium (B5)

Langkah Pertama yang dilakukan dalam perhitungan metode AHP adalah :

1. Melakukan Perhitungan pembobotan keseluruhan kriteria .

Tabel 1. Matriks Untuk Pembobotan Semua Kriteria

\begin{tabular}{cccccc}
\hline & $\mathrm{K} 1$ & $\mathrm{~K} 2$ & $\mathrm{~K} 3$ & $\mathrm{~K} 4$ & $\mathrm{~K} 5$ \\
\hline $\mathrm{K} 1$ & 1 & 3 & 5 & 3 & 7 \\
\hline $\mathrm{K} 2$ & $1 / 3$ & 1 & 2 & 3 & 4 \\
\hline $\mathrm{K} 3$ & $1 / 5$ & $1 / 2$ & 1 & 3 & 3 \\
\hline $\mathrm{K} 4$ & $1 / 3$ & $1 / 3$ & $1 / 3$ & 1 & 3 \\
\hline $\mathrm{K} 5$ & $1 / 7$ & $1 / 4$ & $1 / 3$ & $1 / 3$ & 1 \\
\hline
\end{tabular}

Tabel 2. Matriks Faktor Pembobotan Hirarkis Semua Kriteria disederhanakan.

\begin{tabular}{cccccc}
\hline & K1 & K2 & K3 & K4 & K5 \\
\hline K1 & 1000 & 3000 & 5000 & 3000 & 7000 \\
\hline K2 & 0,333 & 1000 & 2000 & 3000 & 4000 \\
\hline K3 & 0,200 & 0,250 & 1000 & 3000 & 3000 \\
\hline K4 & 0,333 & 0,333 & 0,333 & 1000 & 3000 \\
\hline K5 & 0,143 & 0,250 & 0,333 & 0,333 & 1000 \\
\hline
\end{tabular}

Untuk mendapatkan Nilai eigen maksimum ( $\lambda$ maksimum) dapat dicari dengan cara menjumlahkan hasil perkalian dari jumlah kolom dengan eigen vektor.

Maka nilai eigen maksimum adalah :

$$
\begin{aligned}
& \alpha_{\text {max }}=(2,010 * 0,469)+(5,083 * 0,221)+ \\
& (8,667 * 0,154)+(10,333 * 0,107)+ \\
& (18,000 * 0,049) \\
& =5,391) \\
& C I=\frac{\alpha_{\text {max }}-n}{n-1}=\frac{5,391-5}{5-1}=\frac{0,391}{4}=0,098
\end{aligned}
$$

Untuk $\mathrm{N}=5$ maka RI nya adalah 1,120

$$
C R==\frac{C I}{R I}=\frac{0,098}{1,120}=0,087
$$

Dikarenakan CR $<0.087$ Maka prefensi responden didapatkan konsisten

Tabel 3 .Matriks Faktor Pembobotan Hirarkis yang dinormalkan untuk Semua Kriteria

\begin{tabular}{cccccccc}
\hline & Daun & Warna & $\begin{array}{c}\text { Batang dan } \\
\text { Cabang }\end{array}$ & Akar & Tanah & $\sum$ & Eigen Vector \\
\hline B1 & 0,498 & 0,590 & 0,577 & 0,290 & 0,389 & 2,344 & 0,469 \\
\hline B2 & 0,166 & 0,197 & 0,231 & 0,290 & 0,222 & 1,106 & 0,221 \\
\hline B3 & 0,100 & 0,098 & 0,115 & 0,290 & 0,167 & 0,770 & 0,154 \\
\hline B4 & 0,166 & 0,066 & 0,038 & 0,097 & 0,167 & 0,533 & 0,107 \\
\hline B5 & 0,071 & 0,049 & 0,038 & 0,032 & 0,056 & 0,247 & 0,049 \\
\hline
\end{tabular}

Tabel 4 .Nilai Random Indeks (RI)

\begin{tabular}{ccccccccccc}
\hline $\mathrm{n}$ & 1 & 2 & 3 & 4 & 5 & 6 & 7 & 8 & 9 & 10 \\
\hline $\mathrm{R} 1$ & 0,000 & 0,000 & 0,580 & 0,900 & 1,120 & 1,240 & 1,320 & 1,410 & 1,450 & 1,490 \\
\hline
\end{tabular}


DOI: https://doi.org/10.33330/jurteksi.v7i2.1029

Available online at http://jurnal.stmikroyal.ac.id/index.php/jurteksi

2. Lakukan Pencarian Vektor Prioritas

Tabel 5. Matriks Faktor Pembobotan Hirarki untuk Semua Kriteriaa

\begin{tabular}{lccccc}
\hline & Aglo & $\begin{array}{c}\text { Mon- } \\
\text { stera }\end{array}$ & $\begin{array}{c}\text { Golci } \\
\mathrm{n}\end{array}$ & $\begin{array}{c}\text { Kaktu } \\
\mathrm{s}\end{array}$ & $\begin{array}{c}\text { Kala- } \\
\text { dium }\end{array}$ \\
\hline Aglo & 1000 & 3000 & 5000 & 3000 & 7000 \\
\hline $\begin{array}{l}\text { Mon- } \\
\text { stera }\end{array}$ & 0,333 & 1000 & 2000 & 3000 & 4000 \\
\hline $\begin{array}{l}\text { Golci } \\
\mathrm{n}\end{array}$ & 0,200 & 0,250 & 1000 & 3000 & 3000 \\
\hline $\begin{array}{l}\text { Kaktu } \\
\text { s }\end{array}$ & 0,333 & 0,333 & 0,333 & 1000 & 3000 \\
\hline $\begin{array}{l}\text { Kala- } \\
\text { dium }\end{array}$ & 0,143 & 0,250 & 0,333 & 0,333 & 1000 \\
\hline
\end{tabular}

Vektor Posisi :

3. Lakukan Perhitungan terhadap Faktor Evaluasi untuk Kriteria Daun

Matriks Faktor Evaluasi terhadap Kriteria Daun disederhanakan kemudian dinormalkan sehingga diperoleh hasil pada tabel 6. Untuk mendapatkan Nilai eigen maksimum ( $\lambda$ maksimum) dapat dicari dengan cara menjumlahkan hasil perkalian jumlah kolom dengan eigen vector sehingga diperoleh nilai $\mathrm{CR}<$ 0.098. Dikarenakan CR $<0.098$ Maka prefensi responden didapatkan konsisten.

4. Lakukan Perhitungan Faktor Evaluasi untuk Kriteria Warna

Matriks Faktor Evaluasi untuk Kriteria Warna disederhanakan selanjutnya dinormalkan sehingga dihasilkan tabel 7. Untuk mendapatkan Nilai eigen maksimum ( $\lambda$ maksimum) dapat dicari dengan cara menjumlahkan hasil perkalian jumlah kolom dengan eigen vector seperti pada persamaan sebelumnya.

Maka diperoleh nilai CR $<0.092$ Maka prefensi responden didapatkan konsisten

5. Lakukan Perhitungan Faktor Evaluasi untuk Kriteria Batang dan Cabang Matriks Faktor Evaluasi untuk Kriteria

$$
\begin{aligned}
& \sqrt[5]{1 \times 3 \times 5 \times 3 \times 7}=3,160 \\
& \sqrt[5]{0,333 \times 1 \times 2 \times 3 \times 4}=1,512 \\
& \sqrt[5]{0,200 \times 0,250 \times 1 \times 3 \times 3}=0,852 \\
& \sqrt[5]{0,333 \times 0,333 \times 0,333 \times 1 \times 3}=0,644 \\
& \sqrt[5]{0,143 \times 0,250 \times 0,333 \times 0,333 \times 1}=0,331 \\
& \sum=6,499
\end{aligned}
$$

Vektor Prioritasnya :

- $3,160: 6,499=0,486$

- $0,852: 6,499=0,131$

- $1,512: 6,499=0,233$

- $0,644: 6,499=0,099$

- $0,331: 6,499=0,051$

Batang dan Cabang disederhanakan kemudian dinormalkan sehingga menghasilkan data pada tabel 8. Untuk mendapatkan Nilai eigen maksimum ( $\lambda$ maksimum) dapat dicari dengan cara menjumlahkan hasil perkalian jumlah kolom dengan eigen vektor. Maka nilai eigen maksimum. Dikarenakan CR < 0.089 Maka prefensi responden didapatkan konsisten.

6. Perhitungan Faktor Evaluasi untuk Kriteria Akar

Matriks Faktor Evaluasi untuk Akar disederhanakan kemudian dinormalkan sehingga diperoleh hasil pada tabel 9.

Untuk mendapatkan Nilai eigen maksimum ( $\lambda$ maksimum) dapat dicari dengan cara menjumlahkan hasil perkalian jumlah kolom dengan eigen vector sehingga diperoleh nilai $\mathrm{CR}>0,100$. Dikarenakan CR > 0,100 Maka prefensi responden didapat tidak konsisten, dikarenakan banyaknya orang yang kurang bisa memilih tanaman berdasarkan akar tanaman. 
DOI: https://doi.org/10.33330/jurteksi.v7i2.1029

Available online at http://jurnal.stmikroyal.ac.id/index.php/jurteksi

Tabel 6. Matriks Faktor Evaluasi untuk Daun dinormalkan

\begin{tabular}{cccccccc}
\hline & B1 & B2 & B3 & B4 & B5 & $\sum$ & Eigen Vektor \\
\hline B1 & 0,576 & 0,632 & 0,571 & 0,488 & 0,438 & 2,705 & 0,541 \\
\hline B2 & 0,144 & 0,158 & 0,229 & 0,140 & 0,188 & 0,858 & 0,172 \\
\hline B3 & 0,115 & 0,079 & 0,114 & 0,279 & 0,125 & 0,713 & 0,143 \\
\hline B4 & 0,082 & 0,079 & 0,029 & 0,070 & 0,188 & 0,447 & 0,089 \\
\hline B5 & 0,082 & 0,053 & 0,057 & 0,023 & 0,063 & 0,278 & 0,056 \\
\hline
\end{tabular}

Tabel 7. Matriks Faktor Evaluasi untuk Warna dinormalkan

\begin{tabular}{cccccccc}
\hline & B1 & B2 & B3 & B4 & B5 & $\sum$ & Eigen Vektor \\
\hline B1 & 0,498 & 0,517 & 0,515 & 0,387 & 0,412 & 2,329 & 0,466 \\
\hline B2 & 0,249 & 0,259 & 0,309 & 0,194 & 0,294 & 1,304 & 0,261 \\
\hline B3 & 0,100 & 0,086 & 0,103 & 0,323 & 0,118 & 0,729 & 0,146 \\
\hline B4 & 0,083 & 0,086 & 0,021 & 0,065 & 0,118 & 0,372 & 0,074 \\
\hline B5 & 0,071 & 0,052 & 0,052 & 0,032 & 0,059 & 0,265 & 0,053 \\
\hline
\end{tabular}

Tabel 8. Matriks Faktor Evaluasi untuk Batang dan Cabang dinormalkan

\begin{tabular}{cccccccc}
\hline & B1 & B2 & B3 & B4 & B5 & $\sum$ & Eigen Vektor \\
\hline B1 & 0,550 & 0,634 & 0,517 & 0,452 & 0,333 & 2,486 & 0,497 \\
\hline B2 & 0,183 & 0,211 & 0,310 & 0,323 & 0,238 & 1,266 & 0,253 \\
\hline B3 & 0,110 & 0,070 & 0,103 & 0,129 & 0,286 & 0,699 & 0,140 \\
\hline B4 & 0,079 & 0,042 & 0,052 & 0,065 & 0,095 & 0,332 & 0,066 \\
\hline B5 & 0,079 & 0,042 & 0,017 & 0,032 & 0,048 & 0,218 & 0,044 \\
\hline
\end{tabular}

Tabel 9. Matriks Faktor Evaluasi untuk akar dinormalkan

\begin{tabular}{cccccccc}
\hline & B1 & B2 & B3 & B4 & B5 & $\sum$ & Eigen Vektor \\
\hline B1 & 0,111 & 0,043 & 0,117 & 0,222 & 0,160 & 0,654 & 0,131 \\
\hline B2 & 0,222 & 0,087 & 0,097 & 0,056 & 0,040 & 0,502 & 0,100 \\
\hline B3 & 0,556 & 0,522 & 0,585 & 0,556 & 0,560 & 2,778 & 0,556 \\
\hline B4 & 0,056 & 0,174 & 0,117 & 0,111 & 0,160 & 0,618 & 0,124 \\
\hline B5 & 0,056 & 0,174 & 0,084 & 0,056 & 0,080 & 0,449 & 0,090 \\
\hline
\end{tabular}

Tabel 10. Matriks Faktor Evaluasi untuk Kriteria Tanah yang dinormalkan

\begin{tabular}{cccccccc}
\hline & B1 & B2 & B3 & B4 & B5 & $\sum$ & Eigen Vektor \\
\hline B1 & 0,490 & 0,557 & 0,467 & 0,323 & 0,350 & 2,186 & 0,437 \\
\hline B2 & 0,245 & 0,278 & 0,374 & 0,452 & 0,250 & 1,599 & 0,320 \\
\hline B3 & 0,098 & 0,070 & 0,093 & 0,129 & 0,250 & 0,640 & 0,128 \\
\hline B4 & 0,098 & 0,040 & 0,047 & 0,065 & 0,100 & 0,349 & 0,070 \\
\hline B5 & 0,070 & 0,056 & 0,019 & 0,032 & 0,050 & 0,227 & 0,045 \\
\hline
\end{tabular}

7. Perhitungan Faktor Evaluasi untuk Kriteria Tanah

Matriks Faktor Evaluasi untuk
Tanah disederhanakan kemudian dinormalkan sehingga menghasilkan data pada tabel 10. Untuk mendapatkan Nilai 
eigen maksimum ( $\lambda$ maksimum) dapat dicari dengan cara menjumlahkan hasil perkalian jumlah kolom dengan eigen vector sehingga diperoleh nilai $\mathrm{CR}<$ 0,089. Dikarenakan CR $<0,089$ Maka prefensi responden didapatkan konsisten. Lakukan Perhitungan Total Ranking yang didapatkan. Langkah selanjutnya yaitu mencari total rangking untuk masing-masing jenis tanaman dengan cara mengalikan faktor evaluasi masingmasing alternatif dengan faktor bobot

Setelah dilakukan analisa perhitungan maka didapatkan hasil seperti berikut :

$\begin{array}{ll}\text { Aglonema } & =0,459 \\ \text { Monstera } & =0,204 \\ \text { Kaktus } & =0,085 \\ \text { Gelombang Cinta } & =0,183 \\ \text { Kaladium } & =0,057\end{array}$

Dari perhitungan diatas tanaman hias yang banyak diminati dan harus ditanam ditaman kota adalah Aglonema karena banyak disukai oleh masyarakat untuk penghijauan taman kota.

\section{SIMPULAN}

Dengan aplikasi Sistem Pendukung Keputusan ini dapat membantu dinas tanaman kota dalam menentukan keputusan dalam menentukan tanaman yang layak untuk di tanam dan diperbanyak pada taman kota, penentuan jenis tanaman yang akan ditanam disesuaikan dengan kondisi lahan pada taman kota dan dilakukan dengan cepat serta ditunjang dengan Interface bahasa pemograman yang menarik (User Friendly) dapat mengurangi kejenuhan penggunanya.

\section{DAFTAR PUSTAKA}

[1] L. Hernando, "Sistem Pendukung
Keputusan Untuk Penerimaan Karyawan Baru Berbasis Client Server," JURTEKSI (Jurnal Teknol. dan Sist. Informasi), vol. 6, no. 3, pp. 239-246, 2020, [Online]. Available: https://jurnal.stmikroyal.ac.id/inde x.php/jurteksi/article/download/67 $1 / 412$.

[2] I. A. Huda, "Perkembangan Teknologi Informasi Dan Komunikasi ( Tik ) Terhadap Kualitas Pembelajaran," $J$. Pendidik. dan KONSELING, vol. 1, no. 2, pp. 143-149, 2020.

[3] U. Islam, N. Raden, and I. Lampung, "PERAN TEKNOLOGI INFORMASI DAN KOMUNIKASI DALAM PENDIDIKAN Haris Budiman.," vol. 8, no. I, pp. 31-43, 2017.

[4] A. H. Hasugian and H. Cipta, "Pengertian Sistem Pendukung Keputusan," J. Ilmu Komput. dan Inform., vol. 02, no. April, pp. 1430, 2018.

[5] R. M. Candra, "Sistem Pendukung Keputusan Pemilihan Sekolah Anak Dengan Menggunakan Metode Analytical Hierarchy Process ( AHP ) Dan Metode Perbandingan Eksponensial ( MPE )," vol. 3, no. 1, pp. 31-34, 2017.

[6] Sarmadi and Effiyaldi, "Analisis dan Perancangan Sistem Pendukung Keputusan Pemilihan Kendaraan Roda Dua Menggunakan Metode Simple Additive Weighting (SAW)(Studi Kasus : PT. Sinar Sentosa)," J. Manaj. Sist. Inf., vol. 3, no. 1, pp. 911-921, 2018.

[7] Y. I. Kurniawan, "Sistem Pendukung Keputusan Penentuan Kelolosan Beasiswa Sekolah Menengah Kejuruan (SMK) 
menggunakan Metode Fuzzy," J. Tek. Elektro, vol. 9, no. 1, pp. 1317, 2017, doi: 10.15294/jte.v9i1.9322.

[8] Sriani and R. A. Putri, "Analisa Sistem Pendukung Keputusan Mengunakan Metode TOPSIS Untuk Sistem Penerimaan Pegawai Pada SMA Al Washliyah Tanjung Morawa," J. Ilmu Komput. dan Inform., vol. 02, no. April, pp. 4046, 2018.

[9] M. Megawaty and M. Ulfa, "Decision Support System Methods: A Review," J. Inf. Syst. Informatics, vol. 2, no. 1, pp. 192201, 2020, doi: 10.33557/journalisi.v2i1.63.

[10] T. Informatika, M. Kinerja, and T. Kependidikan, "Perancangan
Decision Support System Dalam Monitoring Kinerja Tenaga Kependidikan Stmik," vol. 2, no. 2, pp. 127-132, 2017.

[11] A. Munthafa and H. Mubarok, "Penerapan Metode Analytical Hierarchy Process Dalam Sistem Pendukung Keputusan Penentuan Mahasiswa Berprestasi," J. Siliwangi, vol. 3, no. 2, pp. 192201, 2017.

[12] R. Umar, A. Fadlil, and Y. Yuminah, "Sistem Pendukung Keputusan dengan Metode AHP untuk Penilaian Kompetensi Soft Skill Karyawan," Khazanah Inform. J. Ilmu Komput. dan Inform., vol. 4, no. 1, p. 27, 2018, doi: 10.23917/khif.v4i1.5978. 